NBER WORKING PAPER SERIES

\title{
THE COSTS AND BENEFITS OF CARING: AGGREGATE BURDENS OF AN AGING POPULATION
}

\author{
Finn Kydland \\ Nick Pretnar \\ Working Paper 25498 \\ http://www.nber.org/papers/w25498 \\ NATIONAL BUREAU OF ECONOMIC RESEARCH \\ 1050 Massachusetts Avenue \\ Cambridge, MA 02138 \\ January 2019
}

Nick Pretnar acknowledges support from the National Science Foundation Graduate Research Fellowship under Grant No. DGE1252522. We would like to thank seminar participants at the University of California - Santa Barbara, Carnegie Mellon University, the University of Missouri, the Spring 2018, Midwest Macroeconomics Conference at the University of Wisconsin, and the 2018 Society for Economic Dynamics Conference at the Instituto Tecnológico Autónomo de México (ITAMS) in Mexico City. Special thanks to Laurence Ales, Javier Birchenall, Ali Shourideh, Joe Haslag, Peter Rupert, Roozbeh Hosseini, Tim Kehoe, Ariel Zetlin-Jones, and Bill Bednar for their helpful comments. The views expressed herein are those of the authors and do not necessarily reflect the views of the National Bureau of Economic Research.

NBER working papers are circulated for discussion and comment purposes. They have not been peer-reviewed or been subject to the review by the NBER Board of Directors that accompanies official NBER publications.

(C) 2019 by Finn Kydland and Nick Pretnar. All rights reserved. Short sections of text, not to exceed two paragraphs, may be quoted without explicit permission provided that full credit, including $\odot$ notice, is given to the source. 
The Costs and Benefits of Caring: Aggregate Burdens of an Aging Population

Finn Kydland and Nick Pretnar

NBER Working Paper No. 25498

January 2019

JEL No. D15,J14,J22,O40

\begin{abstract}
$\underline{\text { ABSTRACT }}$
Throughout the 21st century, population aging in the United States will lead to increases in the number of elderly people requiring some form of living assistance which, as some argue, is to be seen as a burden on society, straining old-age insurance systems and requiring younger agents to devote an increasing fraction of their time toward caring for infirm elders. Given this concern, it is natural to ask how aggregate GDP growth is affected by such a phenomenon. We develop an overlapping generations model where young agents face idiosyncratic risk of contracting an oldage disease, like for example Alzheimer's or dementia, which adversely affects their ability to fully enjoy consumption. Young agents care about their infirm elders and can choose to supplement elder welfare by spending time taking care of them. Through this channel, aggregate GDP growth endogenously depends on young agents' degree of altruism. We calibrate the model and show that projected population aging will lead to future reductions in output of $17 \%$ by 2056 and $39 \%$ by 2096 relative to an economy with a constant population distribution. Curing diseases like Alzheimer's and dementia can lead to a compounded output increase of 5.4\% while improving welfare for all agents.
\end{abstract}

Finn Kydland

Department of Economics

University of California, Santa Barbara

Santa Barbara, CA 93106-9210

and NBER

kydland@econ.ucsb.edu

Nick Pretnar

Carnegie Mellon University

Tepper School of Business

5000 Forbes Ave.

Pittsburgh, PA 15213

npretnar@cmu.edu 


\section{Introduction}

For the United States and other developed countries, population aging will increase the absolute number of individuals requiring some form of elder care. ${ }^{1}$ Microeconomic evidence suggests that caring for infirm older adults requires substantial resources, both in terms of market-traded services and the off-market time of family members. As an example, the Alzheimer's Association estimates that caring for individuals diagnosed with Alzheimer's and dementia is almost triple the cost of caring for non-diagnosed individuals. While approximately $70 \%$ of these costs of care are covered by state and federal social insurance programs, Hurd et al. (2013) estimates that the time-value of informal care provided by family members in 2011 amounted to between $\$ 50$ billion and $\$ 106$ billion. Recent empirical evidence suggests that many working-age adults spend substantial shares of their available time providing informal care for sick and diseased elders with the average adult who cares for another infirm adult spending 5.18 hours per week doing so. Adults who provide informal care work 1.22 hours per week less and enjoy 3.96 hours less leisure time. ${ }^{2}$ The National Institutes of Health, the World Health Organization, and others have warned that the costs of providing assisted-living care for older adults could balloon as the population ages, suggesting that aggregate economic outcomes will be adversely affected by this phenomenon. ${ }^{3}$ We show that the ballooning number of elderly people requiring living assistance will have a modest impact on aggregate economic growth independent of the substantial impacts imposed by aging itself. We find that reducing incidence of high cost-of-care old-age diseases can improve welfare for both diseased and healthy agents in a general equilibrium environment.

\footnotetext{
${ }^{1}$ We use the terms "elder care," "informal care," and "assisted-living care" synonymously to refer to any kind of assistance received by diseased elderly individuals to perform day-to-day life functions.

${ }^{2}$ All time-use estimates are population weighted averages over the period 2003-2016 taken from the American Time Use Survey, from here on ATUS (Bureau of Labor Statistics 2017).

${ }^{3}$ See U.S. studies on the implications of aging from the National Institute on Aging (2011), National Research Council (2001), and Knickman and Snell (2002). Also, for costs associated with caring for elderly individuals with dementia and Alzheimer's, see Alzheimer's Association (2011), Hurd et al. (2013), and Lepore, Ferrell, and Wiener (2017).
} 
Our findings also confirm previous studies that showed population aging in general has a large, negative impact on aggregate output growth rates. In our baseline calculation, holding constant the risk rate of acquiring a debilitating, welfare-reducing disease, we project average annual U.S. GDP growth to be 2.2\% over the period 2016-2056 and 2.1\% over the period 2016-2096. Eliminating the risk of needing long-term assisted-living care marginally increases projected future average annual growth rates for the United States economy over the period 2016-2056 by 10 basis points relative to the baseline. As in Hubbard, Skinner, and Zeldes (1995) and Prescott (2004) social insurance programs in a pay-as-you-go (PAYGO) structure crowd out investment, reducing long-run growth rates relative to a tax-free environment. In the presence of intergenerational transfers of offmarket time from young to old, lifetime welfare increases when social insurance tax rates fall as savings and investment increase. Young agents expect to enjoy being cared for by their offspring when old and plan for this spillover effect when choosing savings. This is because endogenous time transfers from young to old of informal care can help offset the adverse welfare implications of incomplete markets for insurance against oldage welfare shocks. Yet, while reducing social insurance taxes may increase expected lifetime utility, a reduction is not necessarily Pareto improving if the working-age share of adults is low. This is because old agents afflicted with a welfare-reducing disease are made worse off as taxes fall and the number of workers is small enough. In various counterfactual simulations we explore the implications of these trends under different population growth rates and different adverse shock probabilities.

The paper proceeds as follows. In Section 2 we discuss the population trends and cost estimates associated with the prevalence of high cost-of-care old-age diseases, while also summarizing available data on the allocation of time to care for infirm elders. In Section 3 we outline an OLG model that captures the features discussed in Section 2 . In Section 4 , we calibrate this model to match observed data points. In Section 5 we simulate counterfactuals to understand how population changes affect long-run economic trends. 
In Section 6 we conclude.

\section{Background \& Discussion}

The primary motivation for our undertaking is to understand how population aging affects aggregate economic outcomes when members face ex-post idiosyncratic risk to oldage welfare. While the effects of population aging have been discussed in many contexts, few studies have analyzed general equilibrium outcomes when young people save to insure against idiosyncratic risk that directly impacts old-age consumption utility. ${ }^{4}$ The closest study that comes to mind is that of Hall and Jones (2007) who model health risk as endogenously affecting survival rates, along with a health status component in utility. ${ }^{5}$ To the best of our knowledge nobody has attempted to place idiosyncratic endogenous health risk into a model where young agents provide informal hospice care to ailing loved ones. Our undertaking thus contextualizes diseases like dementia, including Alzheimer's, and other idiosyncratic old-age welfare shocks within an economic framework that features long-term informal, assisted-living care.

There have been no studies, to our knowledge, that estimate the impacts of providing informal care off-market on general equilibrium economic outcomes. This is important because an aging population will likely lead to higher levels of informal care being provided by young people to old people. ${ }^{6}$ Several studies have examined how provisions of informal care impact individual labor force participation and earnings (Muurinen 1986; Carmichael, Charles, and Hulme; Leigh 2010; Van Houtven, Coe, and Skira 2013). Informal caregivers who also participate in the formal labor force work on average 3 to 10 hours less per week than their non-caregiving peers (Van Houtven, Coe, and Skira

\footnotetext{
${ }^{4}$ We are aware of French and Jones (2011), DeNardi, French, and Jones (2010), Edwards (2008), and Palumbo (1999) who look at financial planning decisions within retirement in a partial equilibrium context.

${ }^{5}$ An unpublished study by Azomahou, Diene, and Soete (2009) models health risk as a shock to a health capital stock, as opposed to a direct change in the utility function, which is our approach.

${ }^{6}$ For our purposes, "informal care" encompasses all aspects of care which take place off market. "Formal care" will be used to refer to care paid for on the marketplace. These definitions are consistent with those
} 
2013). Providing informal care can thus lead to considerable earnings losses (Muurinen 1986; Van Houtven, Coe, and Skira 2013). Recent work suggests that substitution rates between formal nursing home care and informal in-home care in the United States depend on individual states' complex Medicaid reimbursement structures (Mommaerts 2016, 2017). Indeed, paid long-term care and unpaid in-home care are imperfect substitutes (Mommaerts 2017). We conjecture that this imperfection is due to trade-offs faced by younger family members who willingly provide informal care to elders. Since providing off-market care requires a time investment, younger family members must weigh the altruistic benefits they receive from caring for older loved ones against the loss in lifetime permanent income due to working less.

Until recently there have been few aggregate data available on the rate at which informal elder care is supplied. In 2011 the American Time Use Survey (ATUS) began asking respondents about time spent engaging in informal care for infirm elders (Bureau of Labor Statistics 2017). These data are available for years 2011 thru 2016, but the number of respondents who participated is small $(N=1066)$. From 2003-2016 ATUS asked respondents how much time they spent caring for or helping adults, not just the elderly, who require assistance. Weighted averages of time use for adults age 25-65, where our primary target variable is "adult care", are presented in Table $17^{78}$ Conditional on providing informal care, individuals work less and have less leisure time.

At first glance, the time-use data suggest that the impact of increasing disease prevalence on the intensive margin of labor supply is significant in magnitude as the population ages. For illustration, if providing adult care is perfectly substitutable with working, then for every 1000 people over the age of $65,3.55$ jobs for individuals under the age of 65 would cease to exist. Consider now the effects of such a change: working less results in in Hurd et al. (2013) and Lepore, Ferrell, and Wiener (2017).

${ }^{7}$ We take the denominator in our weekly time-share calculations to be 112 hours, thus allowing individuals 8 hours of non-allocatable personal time per day.

${ }^{8}$ We choose to use the total "adult care" data point rather than the "elder care" data point due to the small sample size of the latter. Empirical tests show that the differences in weighted averages of both data points are not significantly different from zero. More details are available upon request. 
Table 1: Per-Capita Time Allocation of Adults 25 - 65, (ATUS: 2003-2016)

\begin{tabular}{|c|c|c|c|}
\hline \multicolumn{4}{|c|}{ Whole Population, $N=82995$} \\
\hline & Leisure & Labor & Adult Care \\
\hline Avg. Hrs. per Week & 69.642 & 41.743 & 0.615 \\
\hline Share of Avg. Total Time* & 0.622 & 0.373 & 0.005 \\
\hline \multicolumn{4}{|c|}{ Provide Positive Off-Market Adult Care, $N=9937$} \\
\hline & Leisure & Labor & Adult Care \\
\hline Avg. Hrs. per Week & 66.150 & 40.671 & 5.179 \\
\hline Share of Avg. Total Time* & 0.591 & 0.363 & 0.046 \\
\hline \multicolumn{4}{|c|}{ Provide No Off-Market Adult Care, $N=73058$} \\
\hline & Leisure & Labor & Adult Care \\
\hline Avg. Hrs. per Week & 70.113 & 41.887 & 0 \\
\hline Share of Avg. Total Time* & 0.626 & 0.374 & 0 \\
\hline
\end{tabular}

a reduction in permanent income, resulting in a reduction in investment, resulting in a reduction in aggregate output and social insurance tax receipts. However, our results in Section 5 show that young individuals adjust their time use in response to market conditions, including the population distribution, mitigating the aggregate impacts of this disease risk. In fact, changes in the population distribution alone appear to affect the labor supply greatest along the extensive margin. In steady state simulations, we show that young workers increase work time as the relative population of working-age adults to retirees falls, but this increase on the intensive margin does not offset the negative impacts on total labor supply due to a falling extensive margin.

To understand more broadly how long-run declines in aggregate output are related to population aging, in Figure 1 we plot the working-age population ratio (wapr), i.e. the ratio of adults age 25-65 to adults age 65 and over, along with the HP-filtered trend

\footnotetext{
${ }^{9}$ See Hodrick and Prescott (1997) for more information on the HP filter.
} 


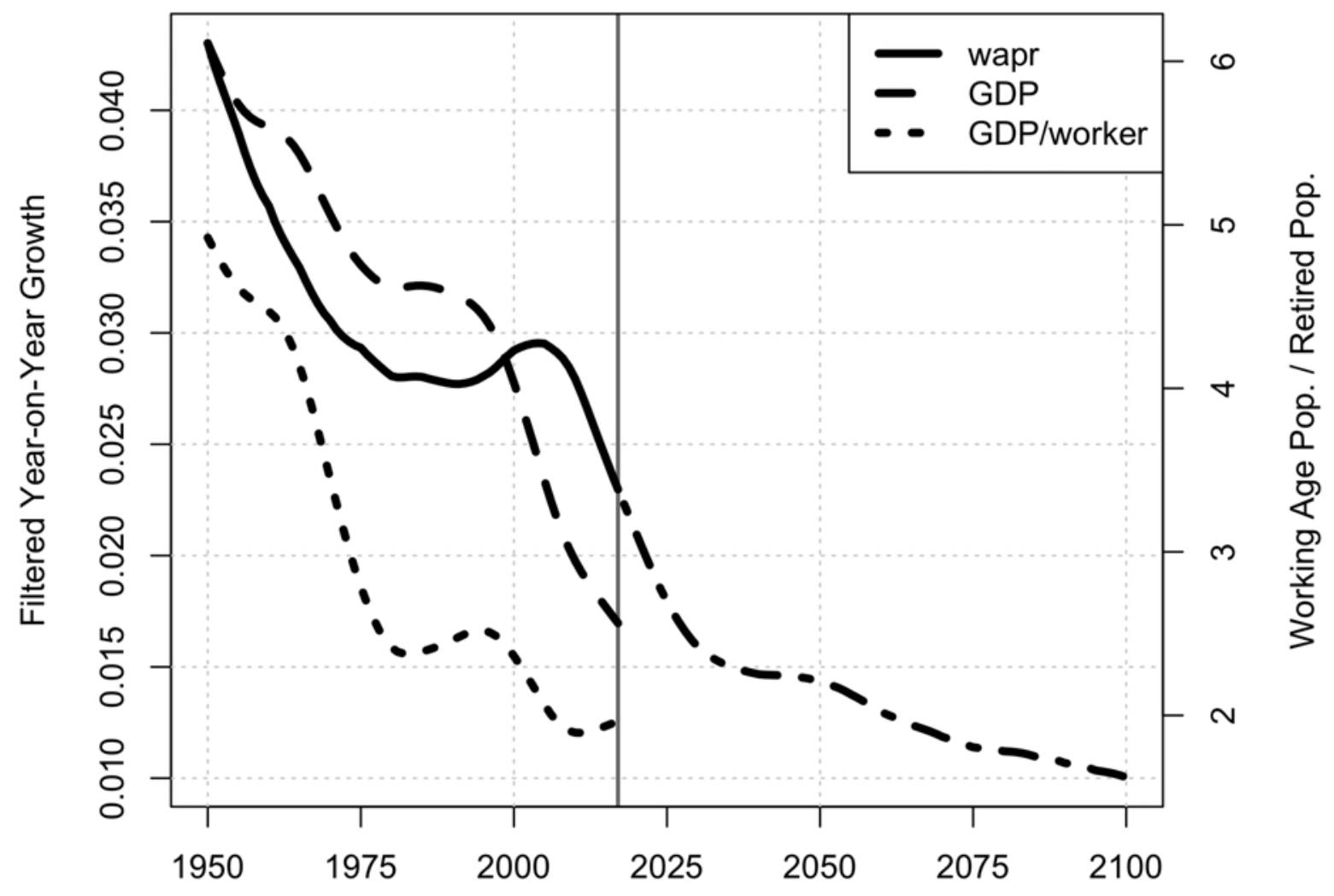

Figure 1: We plot HP-filtered year-on-year net growth: $Y_{t} / Y_{t-1}-1$ for the aggregate case or $\left(Y_{t} / N_{y t}\right) /\left(Y_{t-1} / N_{y, t-1}\right)-1$ for the per-worker case. wapr $r_{t}$ is unfiltered and downloaded from the United Nations: Department of Economic and Social Affairs (2017). The elasticities of filtered aggregate and per-worker growth with respect to wapr $t_{t}$ are 1.487 and 2.395 respectively. If trends continue, we should expect growth rates to decline throughout the 21st century.

of year-on-year aggregate and per-worker GDP growth ( $g_{Y}$ and $g_{Y / N_{y}}$, respectively) for the United States economy since 1950. ${ }^{2}$ When business cycles are removed, the longrun decline in annual GDP growth appears remarkably correlated with the decline in the working-age population ratio. A regression of $\ln g Y, t$ on $\ln w a p r_{t}$ reveals that the elasticity of the filtered trend in output growth with respect to the working-age population ratio is 1.487 , so that a $1 \%$ relative increase in workers leads to an approximate 14 basis point increase in the growth rate. Falling wapr accounts for almost $57 \%$ of the decline in $g Y$ since the 1950s. The magnitude of this correlation affirms some of the alarm bells sounded 
recently in Cooley and Henriksen (2018).

As a motivating example, Alzheimer's disease and dementia impose substantial formal costs on the United States' social insurance system and informal costs on family members tasked with caring for diseased individuals. Total cost estimates for caring for demented elderly individuals range from $\$ 157$ to $\$ 215$ billion (2010 dollars) depending on the method used to impute time value of informal care (Hurd et al. 2013). Within this range, roughly $\$ 11$ billion is covered by Medicare, Medicaid, and Social Security, while the remainder includes both out-of-pocket costs paid by afflicted individuals and their families as well as the time value of unpaid, informal care provided by loved-ones (Hurd et al. 2013). Estimates of total time devoted to informal care for demented persons are not small in magnitude. The Alzheimer's Association estimates that in 2010, 17 billion hours of unpaid care were provided by loved ones to diseased elders, with over $80 \%$ of this time burden born by family members. Further, over $90 \%$ of those afflicted with Alzheimer's or dementia receive some form of informal care on top of care provided by professional hospice services. The spillover effects on working-age adults of shouldering this burden represents an additional societal cost, the impacts of which have not been directly quantified in past studies. As the population ages and Alzheimer's and dementia prevalences increase, it is reasonable to expect that the quantity of informal care provided by working-age adults to elderly adults will increase.

\section{Model}

Agents live a maximum of two periods, though they may die accidentally after their first period of life. ${ }^{10}$ Each period, there exists a population of $N_{y t}$ young households and $N_{\text {ot }}$ old households. ${ }^{11}$ There is only one type of young household and two types of old

\footnotetext{
${ }^{10}$ Young households cannot choose to die, nor can individuals, rather the household is thought to "disappear," in that all of its members have perished before becoming old.

${ }^{11}$ Since agents live only two periods, we use $y$ and $o$ subscripts to denote their ages.
} 
households. Old households can be either diseased, $d_{t}=1$, or non-diseased, $d_{t}=0$. For now, assume the population of young households grows at constant rate $g_{N}$ so that $N_{y t} / N_{y, t-1}=\left(1+g_{N}\right)$, and the probability that a young household in period $t$ lives to be an old household in period $t+1$ is $s_{0, t+1} \cdot 1213$

We model the old agents' consumption process in terms of home production, taking cues from Becker (1965). Young agents can subsidize the home production of diseased old agents' final consumption by supplying them care time $h_{y t}$ outside of formal markets. Diseased individuals thus receive flow utility from final consumption $c_{o t}\left(d_{t}=1\right)$, which is produced in the home by using inputs of this off-market care time they receive from their children $h_{o t}$ and market resources purchased $x_{o t}\left(d_{t}=1\right) .{ }^{14}$ Meanwhile, their healthy peers only use market resources $x_{o t}\left(d_{t}=0\right)$ for production of final consumption because they do not require additional off-market care time from their children. The home production functions we employ for both diseased and non-diseased old are

$$
\begin{aligned}
& c_{o t}\left(x_{o t}\left(d_{t}=1\right), h_{o t}, d_{t}=1\right)=x_{o t}(1)^{1-\sigma} h_{o t}^{\sigma} \quad \sigma \in(0,1) \\
& c_{o t}\left(x_{o t}\left(d_{t}=0\right), d_{t}=0\right)=x_{o t}(0)
\end{aligned}
$$

In Equation (1), $\sigma$ is the elasticity of final consumption with respect to informal care time received. Note that both diseased and non-diseased individuals may purchase hospice care or other health services on the formal market. Such a purchase would fall under market consumption, $x_{o t}\left(d_{t}\right)$. Any additional services received by diseased old that are not accounted for on the formal market would fall under informal care-time received, $h_{o t}$.

Old households have preferences over consumption that depend on health status $d_{t}$. The form of an old individuals' utility function is chosen to satisfy several conditions. First, we assume that individuals infected with a disease require more resources, both

\footnotetext{
${ }^{12}$ We will relax the constant growth, $g_{N}$, assumption in some of our simulations.

${ }^{13}$ The "survival" probability is the probability a young household that enters the economy survives to be an old household next period.

${ }^{14}$ We also refer to $h_{o t}$ as "hospice" care.
} 
market and off-market, to care for than those who are not. It would be unreasonable to assume that these individuals, by consuming more, are necessarily better off than their non-diseased peers (after all, they are sick). Let $u_{o t}\left(c_{o t}\left(d_{t}\right), d_{t}\right)$ denote the flow utility from final consumption for an old individual with disease status $d_{t}$. This brings us to an assumption about an old individual's utility function.

Assumption 1. Suppose $c_{o t}(1)=c_{o t}(0)=c$, where $c$ is any feasible level of final consumption. Then $u_{o t}(c, 1)<u_{o t}(c, 0)$. In words, for each level of final consumption, the non-diseased agent always receives higher consumption utility than the diseased agent.

Assumption 1 ensures that it is always better to be non-diseased than diseased. We choose a Stone-Geary flow utility function for diseased old which satisfies this assumption under certain parameter restrictions:

$$
\begin{aligned}
& u_{o t}\left(c_{o t}(1), d_{t}=1\right)=\ln \left(c_{o t}(1)-v\right) \\
& u_{o t}\left(c_{o t}(0), d_{t}=0\right)=\ln c_{o t}(0)
\end{aligned}
$$

The flow utility parameterizations in (3) and (4) lead to two basic lemmas.

Lemma 1. For all $v>0$, Assumption 1 holds.

Proof. See Appendix A

Lemma 2. If $0<v<c_{o t}(1)-c_{o t}(0)$ then the ratio of the marginal utility of non-diseased consumption to diseased consumption is such that $M U_{o t}(0) / M U_{o t}(1)>1$.

Proof. See Appendix A

Lemma 1 is trivial. Lemma 2 says that for certain combinations of the subsistence parameter $v$ and consumption policies, non-diseased agents benefit more from additional final consumption than diseased agents. In our calibration we find that the premise of Lemma 
2 holds, which is one indicator that in this economy resources are inefficiently allocated in a steady state competitive equilibrium.

Young households use market resources $x_{y t}$ and leisure time $l_{y t}$ to produce a final consumption good $c_{y t}$ according to the home production function:

$$
c_{y t}=x_{y t}^{\gamma} \cdot l_{y t}^{\mu}
$$

Young households additionally supply off-market time $h_{y t}$ to care for their elders, but since this does not affect the final production of their home-produced consumption good, $h_{y t}$ does not enter into Equation (5). Rather, young households exhibit imperfect altruism toward their sick elders, discounting the diseased old household's utility at rate $\eta$. The flow utility of young households is

$$
u_{y t}\left(c_{y t}, h_{y t}\right)=\ln c_{y t}+\eta \cdot \ln \left(c_{o t}\left(h_{y t}, d_{t}=1\right)-v\right)
$$

In addition to consuming and spending time caring for their parents, young agents supply both labor $1-l_{y t}-h_{y t}$ and invest $i_{y t}$ in the market. ${ }^{15}$ Young agents earn a before-tax wage rate $w_{t}$ and pay social insurance taxes on their income at rate $\tau_{t}$.

Old agents do not work but earn a gross return on their assets $a_{y t}$ at rate $R_{t}$ and also receive Social Security and Medicare transfer benefits from the government $T_{t}\left(d_{t}\right)$ which depend on disease status $d_{t}$. Normalize the price of market purchases to 1 each period. For old agents, net outlay must satisfy the budget constraint:

$$
x_{o t}\left(d_{t}\right) \leq R_{t} \cdot a_{y t}+T_{t}\left(d_{t}\right)
$$

Old agents die with certainty at the end of their life and will choose to consume the entirety of their available cash-on-hand. At the end of each period, young agents who

\footnotetext{
${ }^{15}$ Total available time is normalized to 1.
} 
accidentally and unexpectedly die leave behind total net assets (capital) equivalent to $a_{y, t+1} \cdot\left(1-s_{0, t+1}\right) \cdot N_{y t}$. These assets are then distributed evenly and unexpectedly (i.e., "accidentally") as bequests $b_{y, t+1}$ to young agents entering the economy next period according to

$$
b_{y, t+1}=a_{y, t+1} \cdot\left(1-s_{0, t+1}\right) \cdot \frac{N_{y t}}{N_{y, t+1}}
$$

Since returns on investment are compounded at the beginning of the period, young agents earn gross return on these assets $R_{t} \cdot b_{y t}$. Having fully-described the right-hand side of a young agent's budget constraint, their choices of market purchases $x_{y t}$, asset-holdings, and labor-supply must satisfy

$$
x_{y t}+a_{y, t+1} \leq R_{t} \cdot b_{y t}+w_{t} \cdot\left(1-\tau_{t}\right) \cdot\left(1-l_{y t}-h_{y t}\right)
$$

Let $\psi_{t}$ denote the share of old population which is afflicted with a welfare-reducing disease in period $t$. The supply of hospice care by young equals the total amount of hospice care received by diseased old

$$
h_{y t}=\frac{N_{o t} \cdot \psi_{t} \cdot h_{o t}}{N_{y t}}
$$

Let $\rho_{t}=T_{t}(1) / T_{t}(0)$ be the ratio of diseased to non-diseased benefits. The government balances Social Security and Medicare transfers and tax receipts:

$$
N_{o t} \cdot\left(\psi_{t} \cdot \rho_{t} \cdot T_{t}(0)+\left(1-\psi_{t}\right) T_{t}(0)\right) \leq N_{y t} \cdot w_{t} \cdot \tau_{t} \cdot\left(1-l_{y t}-h_{y t}\right)
$$

Young agents do not know whether they will survive to become old and if they do whether they will face a disease that adversely impacts their welfare, but young agents know $\psi_{t}$ and how it evolves, just as they know the survival rate. Thus, they make their 
investment choice both with the aim of smoothing consumption and imperfectly insuring themselves against the adverse welfare effects of contracting some kind of disease such as Alzheimer's or dementia, for example. In this model, given young agents in period $t$ know the distribution of diseased agents in $t+1$, expectations are perfectly rational. Let $\beta$ be the time discount factor. In competitive equilibrium, utility maximizing young agents seek to smooth expected market consumption over the lifecycle according to the expected intertemporal Euler equation:

$$
\underbrace{\frac{\gamma}{x_{y t}}}_{M U_{y}(x)}=\beta \cdot s_{o, t+1} \cdot R_{t+1}[\psi_{t+1} \underbrace{\frac{1-\sigma}{x_{0, t+1}(1)^{1-\sigma} h_{o, t+1}^{\sigma}-v}\left(\frac{h_{0, t+1}}{x_{0, t+1}(1)}\right)^{\sigma}}_{M U_{o}(x(1))}+\left(1-\psi_{t+1}\right) \underbrace{\frac{1}{x_{0, t+1}(0)}}_{M U_{o}(x(0))}]
$$

Since the model contains only idiosyncratic uncertainty, $R_{t+1}$ is pre-determined by the population distribution which is assumed known. Thus young agents choose investment by equating the marginal utility of present market purchases with the discounted expected marginal utility of future consumption given by weighting diseased and nondiseased marginal utilities by the distribution $\psi_{t+1}$. The period $t$ choice of labor supply by young depends on the marginal rate of substitution between consumption and leisure and the marginal rate of substitution between leisure and off-market care time:

$$
\begin{aligned}
\frac{\mu}{l_{y t}} & =\frac{\gamma}{x_{y t}} w_{t}\left(1-\tau_{t}\right) \\
\frac{\mu}{l_{y t}} & =\eta \cdot \frac{\sigma}{x_{o t}(1)^{1-\sigma} h_{o t}^{\sigma}-v}\left(\frac{h_{o t}}{x_{o t}(1)}\right)^{\sigma-1} \frac{N_{y t}}{N_{o t} \psi_{t}}
\end{aligned}
$$

A single firm produces both an investment good $I_{t}$ and a market good $X_{t}$. We assume period $t$ production is Cobb-Douglas $F_{t}\left(K_{t}, L_{t}\right)=z_{t} K_{t}^{\alpha} L_{t}^{1-\alpha}$ where $K_{t}$ and $L_{t}$ are aggregate capital and labor respectively. Let $\delta$ be the net rate of capital depreciation. The rate of return on assets $R_{t}$ and before-tax wages $w_{t}$ are determined by the marginal products of 
capital and labor respectively:

$$
\begin{aligned}
& R_{t}=1+z_{t} \cdot \alpha \cdot\left(\frac{L_{t}}{K_{t}}\right)^{1-\alpha}-\delta \\
& w_{t}=z_{t} \cdot(1-\alpha) \cdot\left(\frac{K_{t}}{L_{t}}\right)^{\alpha}
\end{aligned}
$$

Each period aggregate capital in the economy is only affected by young agents' choice of investment from last period since surviving old agents consume their entire portfolio.

$$
\begin{aligned}
K_{t} & =N_{y, t-1} a_{y t}=\frac{N_{y t}}{1+g_{N}} a_{y t} \\
L_{t} & =N_{y t}\left(1-l_{y t}-h_{y t}\right)
\end{aligned}
$$

Finally, total factor productivity $z_{t}$ grows at constant net rate $g_{z}$.

\subsection{Competitive Equilibrium with Transfers}

Given $g_{N}, g_{z}$, an exogenously specified sequence of probabilities for disease contraction and survival from young to old, $\left\{\psi_{t}, s_{0, t+1}\right\}_{t \geq 0}$, an initial population level $N_{y 0}=1$, an initial total factor productivity level $z_{0}=\left(1+g_{N}\right)^{\alpha}$, and an initial young asset level $a_{y 0}$, a competitive equilibrium with transfers consists of:

i. Sequences of policies for consumers: $\left\{x_{y t}, l_{y t}, h_{y t}, a_{y, t+1}, x_{o t}(1), x_{o t}(0)\right\}_{t \geq 0}$.

ii. Sequences of prices $\left\{R_{t}, w_{t}\right\}_{t \geq 0}$.

iii. Government policies $\left\{T_{t}(1), T_{t}(0), \tau_{t}\right\}_{t \geq 0}$.

such that

a. Young agents' choices satisfy (9) and (12) thru (14).

b. Old agent consumption policies satisfy (7). 
c. Asset return rates and wage rates are (15) and (16).

d. Formal and informal markets clear.

e. The government's budget is balanced.

The beauty of the two period assumption is that it allows us to consider only how changes in the working age to retiree population ratio wapr ${ }_{t}$ affects equilibrium outcomes. This is illustrated in Proposition 1. As a corollary to Proposition 1, we also demonstrate that in this environment, aggregate output growth $g_{Y t}$ depends only on wapr, not generational population levels.

Proposition 1. A competitive equilibrium depends only on $w a p r_{t}$, not the population levels.

Proof. Using (17) and the normalization $z_{0}=\left(1+g_{N}\right)^{\alpha}$, we can write the aggregate resource constraint

$$
\begin{aligned}
N_{y t} \cdot x_{y t} & +N_{o t}\left(\psi_{t} \cdot x_{o t}(1)+\left(1-\psi_{t}\right) \cdot x_{o t}(0)\right)+N_{y t} \cdot a_{y, t+1} \\
\leq & (1-\delta) \frac{N_{y t}}{1+g_{N}} a_{y t}+\left(1+g_{z}\right)^{t} \cdot N_{y t} \cdot a_{y t}^{\alpha}\left(1-l_{y t}+h_{y t}\right)^{1-\alpha}
\end{aligned}
$$

Dividing both sides by $N_{o t}$, we can write

$$
\begin{aligned}
& \text { wapr }_{t} \cdot x_{y t}+\psi_{t} \cdot x_{o t}(1)+\left(1-\psi_{t}\right) \cdot x_{o t}(0)+\text { wapr }_{t} \cdot a_{y, t+1} \\
& \quad \leq(1-\delta) \frac{\text { wapr }_{t}}{1+g_{N}} a_{y t}+\left(1+g_{z}\right)^{t} \cdot \text { wapr }_{t} \cdot a_{y t}^{\alpha} \cdot\left(1-l_{y t}+h_{y t}\right)^{1-\alpha}
\end{aligned}
$$

Note that consumption decisions depend on $R_{t}$ and $w_{t}$. Using (17) and (18), $R_{t}$ and $w_{t}$ do not depend on population levels except through household policies. In (8), under constant $g_{N}, b_{y, t+1}$ can be written

$$
b_{y, t+1}=a_{y, t+1} \cdot\left(1-s_{o}\right) \cdot \frac{1}{1+g_{N}}
$$


In (10) $h_{y t}$ can be written

$$
h_{y t}=\frac{\psi_{t}}{w a p r_{t}} h_{o t}
$$

The government budget constraint in (23) can be written

$$
\left(\psi_{t} \cdot \rho_{t} \cdot T_{t}(0)+\left(1-\psi_{t}\right) T_{t}(0)\right) \leq w_{a p r} \cdot w_{t} \cdot \tau_{t} \cdot\left(1-l_{y t}-h_{y t}\right)
$$

Finally, young household policies must satisfy (12) thru (14). Population levels only enter (14), which can be written

$$
\frac{\mu}{l_{y t}}=\eta \cdot \frac{\sigma}{x_{o t}(1)^{1-\sigma} h_{o t}^{\sigma}-v}\left(\frac{h_{o t}}{x_{o t}(1)}\right)^{\sigma-1} \frac{\text { wapr }_{t}}{\psi_{t}}
$$

Corollary 1. Aggregate growth $g_{Y, t}$ depends only on wapr ${ }_{t}$, not population levels.

Proof. See Appendix A

\subsection{Steady State and Balanced Growth}

To solve for a steady state, we assume a balanced growth path (BGP) and de-trend productivity growth as in Krueger and Ludwig (2007). For now, suppose $\tau_{t}=\tau$ is exogenously fixed. Along a BGP the population of young agents and productivity grow at constant exogenous rates, $g_{N}$ and $g_{z}$. Proposition 2 demonstrates that if survival rates and disease risk are constant, then wapr is constant across time.

Proposition 2. Assume the survival rate $s_{0, t+1}=s_{0}$ is constant and the diseased old distribution $\psi_{t}=\psi$ is stationary. Then along a BGP the working-age population ratio 
wapr is constant and given by

$$
w a p r=\frac{1+g_{N}}{s_{o}}
$$

Proof. See Appendix A

Clearly, the assumption that wapr is constant is unrealistic in practice, as we see that wapr has been falling over time and is projected to continue falling. This fact begs the question as to whether the U.S. economy in the 21st century is in fact on a balanced growth trajectory or rather is exhibiting structural change due to forces such as population aging and potentially associated idiosyncratic welfare risk affecting long-run growth rates. In Section 5 we simulate the future path of aggregate output growth to understand the extent to which falling wapr, coupled with idiosyncratic welfare risk and young agents' altruism, together impact aggregate growth.

\section{Calibration}

For our calibration we set the period length to 40 years and assume young agents enter the economy at age 25 and turn old at age 65 . Our calibration assumes the economy is in steady state in 2016, thus taking the 2016 observed population distribution as the initial steady state distribution. ${ }^{16}$ We choose parameters to match a set of carefully selected data moments from around 2016. Specifically, we calibrate to leisure, labor, and hospice care average time shares from the 2003-2016 ATUS data, the personal savings rate from the "PSAVERT" time series (BEA, 2016) which measures personal savings as a percentage of disposable income, the ratio of diseased to non-diseased consumption computed from estimates made by Hurd et al. (2013), the 2016 consumption and investment shares of output (BEA, 2016), and the 2015 U.S. labor and capital income shares from Penn World

\footnotetext{
${ }^{16}$ Appendix B.0.2 presents the steady state equations.
} 
Table 9.0. Table 2 presents the data moment targets and their simulated model counterparts, while Table 3 presents the calibrated parameter values and their sources.

The calibration requires a couple of assumptions for identification purposes. First, we exogenously set the benefits ratio $\rho$ using estimates by Hurd et al. (2013) and Mommaerts (2016) to get $\rho=1.923 .{ }^{17}$ Thus, diseased agents receive almost double the benefits from the government as non-diseased agents. To calibrate to a steady state assuming it has been de-trended from a BGP, we only have to pick two of $g_{N}, s_{0}$, and wapr, due to Equation (25). We set $g_{N}$ to accommodate growth in the young population since 1976 and wapr to equal the observed population ratio for workers to retirees in 2016. We exogenously fix the parameters $\mu, \gamma$, and $\eta$ to reflect the observed ATUS time-use averages from 20032016. The output elasticity $\alpha$ is chosen to match the average U.S. capital share since World War II. The risk rate $\psi$ is fixed based on estimates from Hurd et al. (2013). We calibrate the subsistence parameter $v$ and intensity of hospice care parameter $\sigma$ to match aggregate data moments, including the ratio of diseased to non-diseased consumption $x_{o}(1) / x_{o}(0)$ taken from estimates in Hurd et al. (2013).

Table 2: Calibration Targets

\begin{tabular}{cccc}
\hline \hline Moment & Model & Data & Source \\
\hline$l_{y}^{*}$ & 0.617 & 0.622 & ATUS, 2003-2016 Avg. \\
$1-l_{y}^{*}-h_{y}^{*}$ & 0.375 & 0.373 & ATUS, 2003-2016 Avg. \\
$h_{y}^{*}$ & 0.008 & 0.005 & ATUS, 2003-2016 Avg. \\
Savings Rate & 0.137 & 0.049 & BEA, 2016 \\
$x_{o}^{*}(1) / x_{o}^{*}(0)$ & 1.315 & 1.360 & Hurd et al. 2013 \\
$X^{*} / Y^{*}$ & 0.812 & 0.680 & Consumption Share, 2016 \\
$I^{*} / Y^{*}$ & 0.188 & 0.320 & Investment Share, 2016 \\
Labor Income Share & 0.645 & 0.600 & Penn World Table 9.0, 2015 \\
Capital Income Share & 0.355 & 0.400 & Penn World Table 9.0, 2015 \\
\hline
\end{tabular}

\footnotetext{
${ }^{17}$ The procedure used to set this parameter is described in detail in Appendix $B$
} 
Table 3: Calibrated Parameter Values

\begin{tabular}{lcc}
\hline \hline & Value & Source \\
\hline$g_{N}$ & 0.660 & Growth in Age 25-65 Pop. (1976-2016) \\
$\delta$ & 0.9517 & 40 years of 6\% annual depreciation \\
$\alpha$ & 0.35 & Post-war avg. capital share (DeJong and Dave 2011) \\
$\beta$ & 0.4457 & Annual discounting of 0.98 over 40 years \\
$\gamma$ & 0.373 & ATUS (2003-2016) avg. work \\
$\mu$ & 0.622 & ATUS (2003-2016) avg. leisure \\
$\eta$ & 0.005 & ATUS (2003-2016) avg. adult care \\
$w a p r$ & 3.475 & U.S. Working-age pop. ratio 2016 (UN) \\
$\tau$ & 0.153 & S.S. + Medicare tax rate 2016 \\
$\rho$ & 1.923 & Ratio of diseased/non-diseased benefits (see Appendix B.0.1) \\
$\psi$ & 0.14 & Risk of contracting dementia (see Hurd et al. 2013) \\
$\nu$ & 0.099 & Subsistence of old (calibrated to match data) \\
$\sigma$ & 0.659 & Intensity of $h_{o t}$ in home production (calibrated to match data) \\
\hline
\end{tabular}

\section{Findings}

\subsubsection{Predicted U.S. Aggregate Output Growth}

We want to understand how well the model predicts different aggregate growth rates when the population is evolving in ways inconsistent with balanced growth. We compute a transition path from starting steady states with wapr equivalent to those observed in 1950,1960,1970, 1980, and 1990, simulating toward a terminal steady state with wapr = 3.475 as observed in 2016. We assume period 0 of the model is in one of the old wapr, and then the economy suddenly changes to $w a p r=3.475$, allowing 200 simulated periods to facilitate convergence to the new steady state. ${ }^{18}$ For each simulation, we set the initial steady state's $\tau$ to the actual employee and employer combined Social Security and Medicare tax rate for the given year. ${ }^{19}$ Productivity growth is set to accommodate the observed average annual private multi-factor (MFP) productivity growth rates for the

\footnotetext{
${ }^{18}$ For a thorough explanation of how to accomplish this simulation technique in an overlapping generations model see the endogenous grid point method of Carroll (2006) and Appendix B of Krueger and Ludwig (2007).

${ }^{19}$ The tax rates are as follows: 3\% (1950), 6\% (1960), 9.6\% (1970), 12.26\% (1980), 15.3\% (1990 and thereafter).
} 
Table 4: Model Performance: Predicted Avg. Annual Growth to 2016

\begin{tabular}{cccccc}
\hline \hline \multicolumn{5}{c}{ Growth in Aggregate Output, (\%) } \\
\cline { 2 - 4 } Data Period & Starting wapr & Model $g_{Y}$ & Data $g_{Y}$ & Implied $g_{z}$ & Data $g_{z}$ \\
\hline $1950-2016$ & 6.111 & 3.121 & 3.096 & 1.177 & 1.197 \\
$1960-2016$ & 5.114 & 2.924 & 3.008 & 1.182 & 1.107 \\
$1970-2016$ & 4.414 & 2.497 & 2.742 & 1.100 & 0.901 \\
$1980-2016$ & 4.075 & 2.203 & 2.630 & 1.268 & 0.876 \\
$1990-2016$ & 4.028 & 1.963 & 2.377 & 1.240 & 0.906 \\
\hline
\end{tabular}

Growth in Output Per Working Age Adult, (\%)

\begin{tabular}{cccccc} 
Data Period & Starting wapr & Model $g_{Y / N_{y}}$ & Data $g_{Y / N_{y}}$ & Implied $g_{z / N_{y}}$ & Data $g_{z} / N_{y}$ \\
\hline $1950-2016$ & 6.111 & 1.212 & 1.952 & 1.985 & 0.074 \\
$1960-2016$ & 5.114 & 1.245 & 1.827 & 1.661 & -0.053 \\
$1970-2016$ & 4.414 & 0.996 & 1.460 & 1.404 & -0.359 \\
$1980-2016$ & 4.075 & 1.081 & 1.413 & 1.194 & -0.320 \\
$1990-2016$ & 4.028 & 1.276 & 1.356 & 1.030 & -0.100 \\
\hline
\end{tabular}

periods 1950-2016, 1960-2016, 1970-2016, 1980-2016, and 1990-2016. ${ }^{20}$ We compare both predicted productivity re-trended aggregate output growth and per-worker re-trended output growth from the first period after the sudden change in working age population ratio to that observed in the data. These values are presented in Table 4 under columns labeled "Model $g_{Y}$ " and "Model $g_{Y / N_{y}}$ " where the former describes aggregate growth and the latter growth per working-age adult. Model predictions slightly undershoot aggregate growth rates for all periods, though the aggregate rates are only off by 20 basis points at most.

We run two additional simulations adjusting $g_{z}$ to match observed $g_{Y}$ and $g_{Y / N_{y}}$. Implied productivity growth from these simulations is presented in columns labeled "Implied $g_{z}$ " and "Implied $g_{z / N_{y}}$ " in Table 4 . In the data, $g_{z / N_{y}}$ is negative since the 1960s when the denominator we use to compute output per-worker is the entire working-age adult population. To reconcile per-worker growth, our model requires growth in produc-

\footnotetext{
${ }^{20} \mathrm{MFP}$ is real value-added output divided by combined inputs - U.S. Bureau of Labor Statistics, Private Business Sector: Multi-factor Productivity [MFPPBS], retrieved from FRED, Federal Reserve Bank of St. Louis; https://fred.stlouisfed.org/series/MFPPBS, Accessed: October 23, 2018.
} 
tivity per-worker to exceed growth in aggregate productivity as can be seen by comparing the "Implied" column of the bottom half of Table 4 to the top half. The model thus appears to do a decent job of matching aggregate output growth but not output per-worker. This is due to the fact that we assume a 40-year transition period regardless of the starting wapr being associated with the year 1950 or 1990. Comparisons between aggregate numbers are not biased by this fact because the aggregate growth rate does not depend on a scaling with the growth rate of newborns entering the economy, $g_{N}$, which must be computed to accommodate the transition from the initial steady state wapr to the terminal one. If we allow for the possibility that perhaps measurements of MFP in the NIPA tables themselves are biased, failing to account for endogeneity due to $g_{z}{ }^{\prime}$ s dependence on the population distribution, then U.S. productivity growth over the second half of the twentieth century has perhaps been overstated, or at the least misunderstood. At first consideration, it is hard to ignore the positive correlation between measured productivity per-worker and wapr. One can think of a number of possible ways in which wapr may affect productivity: younger workers have more energy and work more in order to build up a nest egg from scratch, for example. In the context of our formulation, a relatively large population of retirees could negatively weigh on aggregate productivity by diverting working-age adults' attention from their jobs because they provide informal care. If this explanation were true, $z_{t}$ would be an endogenous function of $w a p r_{t}$, and $g_{z, t}$ would vary in time, falling along with wapr. We do not take a stance on the mechanism by which $z_{t}$ may partially depend endogenously on wapr. Rather, the decomposition in Table 4 illustrates what the $w_{a p r}$-independent component of $g_{z, t}$ would need to be in order to match observed output growth under our parameterization. In general, the results of these simulations show that the given model can accurately predict aggregate growth, suggesting researchers should take our future growth estimates presented in Section 5.1 seriously, affirming the general spirit of the results in Cooley and Henriksen (2018). 


\subsection{Future Growth Under Different Counterfactual Regimes}

One goal of this project is to understand how the welfare risk of contracting a debilitating old-age disease may affect future aggregate output growth while the population is aging. As a baseline, we follow techniques described in Krueger and Ludwig (2007) to simulate a transition path between the calibrated 2016 steady state and a far-off future steady state assuming the population converges after 200 periods to the United Nations predicted, 2096 median-variant population distribution. ${ }^{21}$ We then examine projected growth rates and lifetime welfare under the following policy reforms. First, we consider how the economy evolves when the "dynamically ignorant" government suddenly sets $\tau=0$ one period into the future and households are surprised by this change, failing to anticipate it. ${ }^{22}$ Second, we consider a policy reform where the government decides to fully reimburse working-age adults for their off-market time at the before-tax market wage. ${ }^{23}$ Finally, we simulate a dynamic transition path under unexpected changes to the disease risk rate. We consider growth under a cure by 2056 and a cure by 2096, as well as growth under $10 \%, 20 \%, 50 \%$, and $100 \%$ increases in cross-sectional risk by $2096 .{ }^{24}$ These changes are all based on the value of $\psi=0.14$ used in calibration, taken from estimates of dementia risk for 70 year olds in Hurd et al. (2013). For computational reasons, we assume changes are permanent after 2096 so the economy has some steady state outcome to which to converge.

\footnotetext{
${ }^{21}$ See United Nations: Department of Economic and Social Affairs 2017.

${ }^{22}$ Here, we consider the 2016 wapr $=3.475$ as "present."

${ }^{23}$ Currently, some U.S. state Medicaid programs reimburse family members for care time they provide to Medicaid recipients, though the rates of reimbursement and restrictions vary substantially across states. Current data on state-level Medicaid policies does not appear to be readily available in a central source.

Under this reform, the young agent's budget constraint is:
}

$$
x_{y t}+a_{y, t+1} \leq R_{t} \cdot b_{y t}+w_{t}\left(1-\tau_{t}\right)\left(1-l_{y t}-h_{y t}\right)+w_{t} \cdot h_{y t}
$$

while the government faces budget constraint:

$$
N_{o t} \cdot\left(\psi_{t} \cdot \rho_{t} \cdot T_{t}(0)+\left(1-\psi_{t}\right) T_{t}(0)\right) \leq N_{y t} \cdot\left(w_{t} \cdot \tau_{t} \cdot\left(1-l_{y t}-h_{y t}\right)-w_{t} \cdot h_{y t}\right)
$$

\footnotetext{
${ }^{24}$ For a "cure" we consider a situation where $\psi$ drops to 0.0001 to ensure Inada conditions hold.
} 
Table 5: Growth Under Different Regimes, $g_{z}=1.4 \%$

\begin{tabular}{lcccc}
\hline \hline & & \multicolumn{3}{c}{ Predicted Avg. Annual Growth $g_{Y},(\%)$} \\
\cline { 3 - 5 } Model & Pop. Transition? & $2016-2056$ & $2016-2096$ & $2016-2136$ \\
\hline BGP $(\tau=0.153, \psi=0.14)^{*}$ & No & 2.693 & 2.693 & 2.693 \\
Baseline & Yes & 2.228 & 2.052 & 1.890 \\
\hline$\tau=0$ & Yes & 2.364 & 2.298 & 2.096 \\
\hline Reimbursement of $h_{y t}$ at $w_{t}$ & Yes & 2.224 & 2.074 & 1.912 \\
\hline$\psi_{2056}=0.0001, \psi_{2096}=0.0001$ & Yes & 2.277 & 2.123 & 1.947 \\
$\psi_{2056}=0.07, \psi_{2096}=0.0001$ & Yes & 2.248 & 2.096 & 1.941 \\
$\psi_{2056}=0.146, \psi_{2096}=0.154$ & Yes & 2.226 & 2.047 & 1.884 \\
$\psi_{2056}=0.154, \psi_{2096}=0.168$ & Yes & 2.223 & 2.042 & 1.876 \\
$\psi_{2056}=0.175, \psi_{2096}=0.210$ & Yes & 2.216 & 2.026 & 1.858 \\
$\psi_{2056}=0.21, \psi_{2096}=0.280$ & Yes & 2.203 & 1.997 & 1.822 \\
\hline End-of-period wapr used in simulations: & 2.110 & 1.658 & 1.658 \\
\hline \hline
\end{tabular}

${ }^{*} \tau=0.153$ and / or $\psi=0.14$ unless otherwise noted.

Table 5 presents simulated average annual aggregate output growth rates $\left(g_{Y}\right)$. For the baseline simulations holding $\tau$ and $\rho$ at their observed and calibrated 2016 values, we compare the dynamic transition path of an economy aging according to U.N. projections. Our regime-change counterfactuals operate as follows. First, we suppose that the economy is in the initial 2016 steady state, then the regime change occurs suddenly. For all of these changes, in period $t=2$ right after the 2016 steady state, the economy has changed unexpectedly, but agents have not updated their dynamic plans. We thus simulate the economy for 200 periods to allow for it to converge to the new steady state, which generally happens after only 7-10 model periods anyway. All of our counterfactual simulations occur off a BGP, where the population distribution is evolving exogenously according to U.N. estimates.

From these simulations it is apparent that an aging population substantially reduces growth relative to a BGP where wapr remains constant. In fact this reduction is on the order of 50 basis points annually, leading to compounded aggregate output losses of $17 \%$ 
by 2056 and 39\% by 2096 relative to an economy where wapr held constant at 2016 levels. Though perhaps politically unrealistic, it is illustrative that in this economy setting $\tau=0$ can lead to both Pareto improvements along the dynamic transition path and increases in compounded aggregate output relative to the baseline with population transition $5 \%$ higher by 2056 and $17 \%$ higher by 2096. Figure 2 presents the fully compounded predicted population baseline growth relative to counterfactual growth projections, including the BGP. Implementing a before-tax reimbursement policy while holding $\tau=0.153$ fixed yields Pareto improvements but adversely affects compounded growth relative to the population transition baseline in the first period - output is $0.2 \%$ lower by $2056-$ though growth improves slightly by the end of the century $-1.7 \%$ higher by 2096 . The predicted baseline falls the most relative to BGP, then the tax-free environment, then finally the full cure. Neither stabilizing the population distribution to achieve a BGP nor eliminating Social Security and Medicare are realistically feasible, yet scientists are working to find cures for dementia-like diseases. In the event a cure is found, the model predicts compounded U.S. total output will be 5.4\% higher by 2096 and $6.6 \%$ higher by 2136 relative to the baseline where $\psi=0.14$.

One takeaway we wish to emphasize is that achieving a full cure $-\psi=0.0001$ by 2056 - would have a small impact on growth, increasing $g_{Y}$ by only about 10 basis points. Long-run growth rates and welfare are decreasing in $\psi$. The most striking thing about our simulations under different $\psi$ is that changing the risk rate hardly matters for long-run growth prospects. Rather, the population distribution, regardless of the risk rate, has the largest effect on long-run growth, which can be seen by comparing any of the simulations that account for population transitions with the BGP. All counterfactuals result in anywhere from 60 to 90 basis point relative declines in the average annual growth rate by 2136, and 40 to 70 basis point relative declines by 2096. While this result should mitigate concerns that the burdens of old-age care alone will tamp down growth, we confirm recent findings in Cooley and Henriksen (2018) suggesting a long-run "demographic 


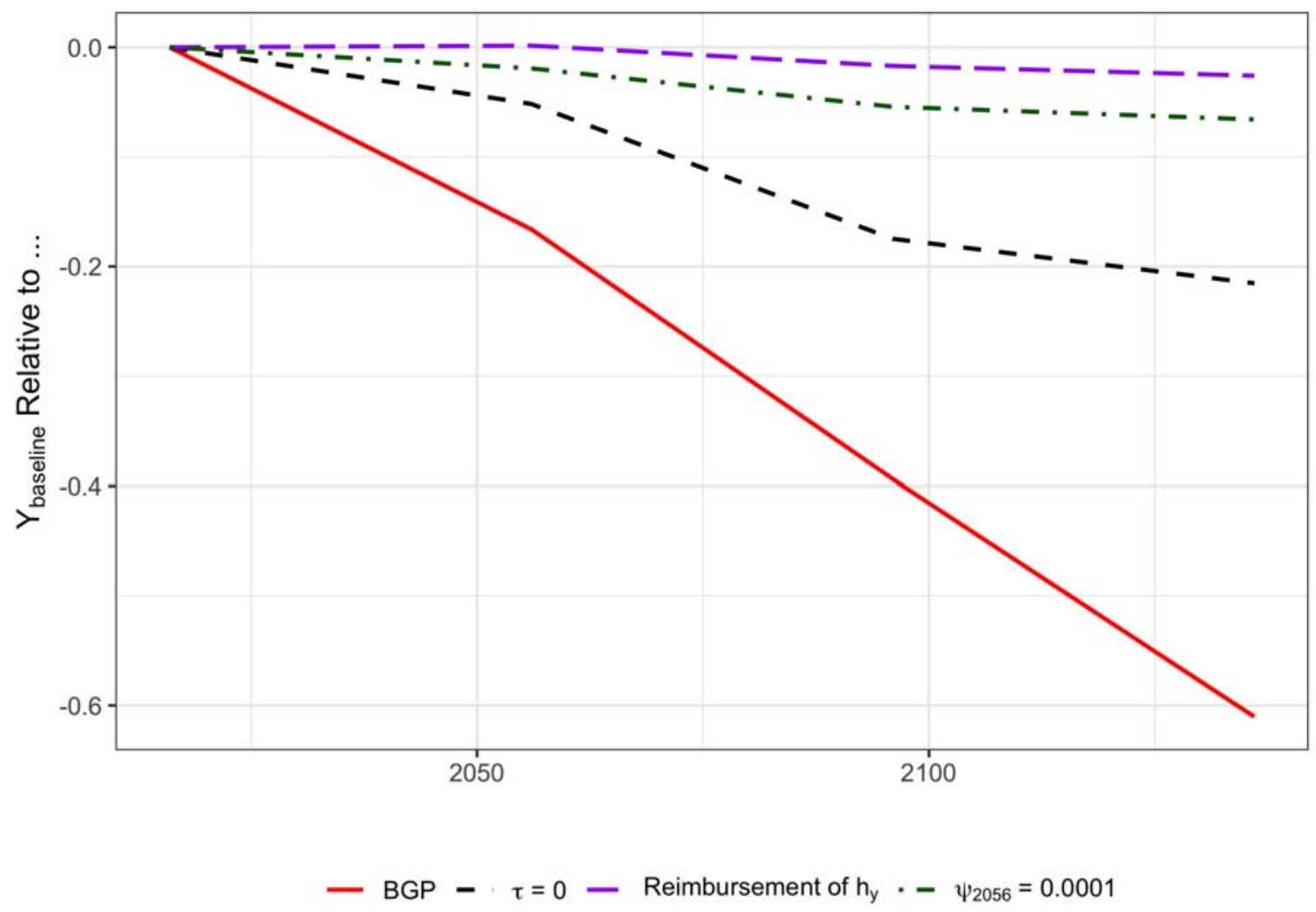

Figure 2: Here we present predicted baseline output relative to various counterfactuals, $\left(Y_{\text {baseline }}-Y_{\text {counter }}\right) / Y_{\text {counter. }}$ A cure for dementia by $2056(\psi=0.0001$; green dashed line $)$ can lead to modest improvements relative to the baseline.

deficit" may be coming to the United States economy.

Yet reducing disease risk, despite having minimal impact on growth, is still welfare improving. Figure 3 compares welfare paths for different possible risk rates, relative to a baseline economy where $\psi=0.14$, as estimated by Hurd et al. (2013). Notice that welfare improves for all agents as $\psi \rightarrow 0$, though risk reduction has the most pronounced effect on diseased agents' welfare, leading to a greater than $6 \%$ lifetime gain relative to the baseline. Next, young agents enjoy higher expected lifetime utility, but are also hit hardest relative to the baseline when $\psi$ increases. This is because children shoulder the burden of increased numbers of diseased old through the altruism mechanism. Meanwhile, Figure 4 compares welfare paths over the 21st century relative to the population transition baseline for the tax-free environment and an economy with a reimbursement 

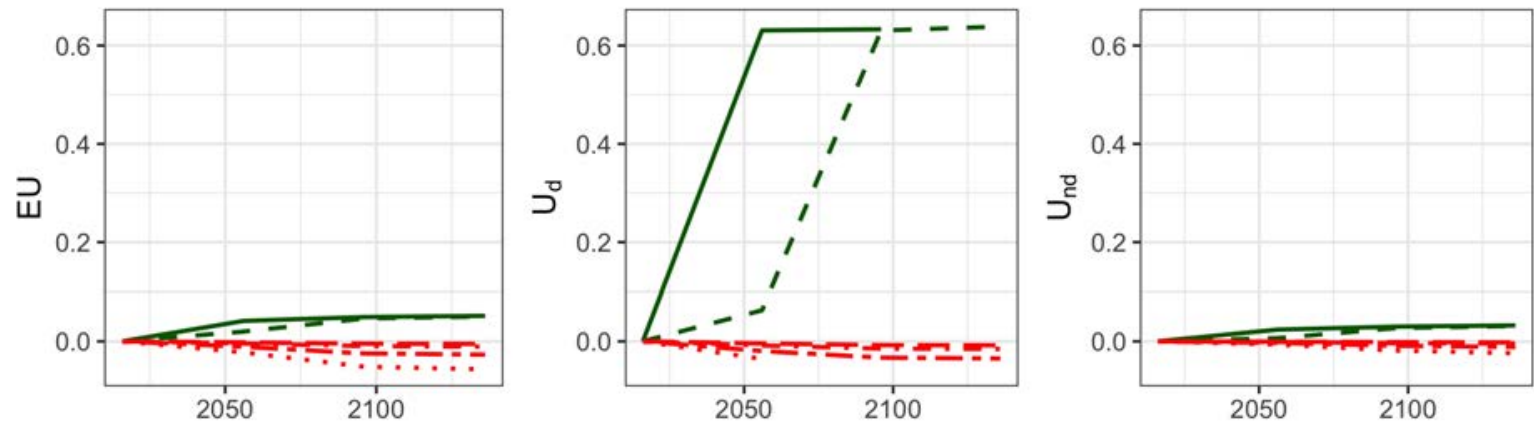

$$
\begin{aligned}
& -\psi_{2056}=0.0001-\psi_{2096}=0.0001-\psi_{2096}=0.154 \\
& -\psi_{2096}=0.168--\psi_{2096}=0.210 \cdots \psi_{2096}=0.280
\end{aligned}
$$

Figure 3: We present welfare as share of the predicted baseline with population transition. Full cures $(\psi \rightarrow 0$; black lines) generate Pareto improvements for all types of agents. As $\psi$ increases (red lines), welfare falls relative to the predicted baseline with $\psi=0.14$.
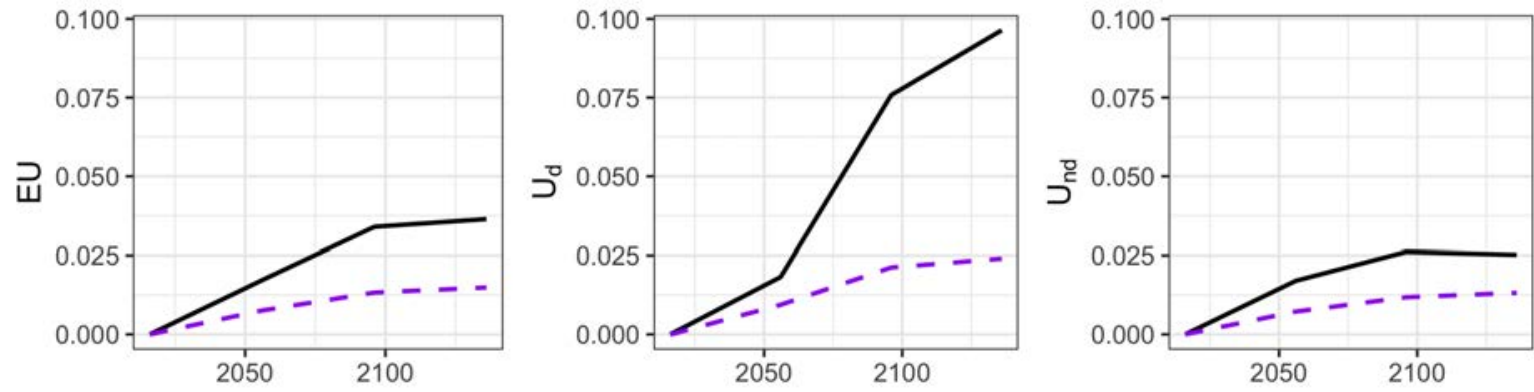

$-\tau=0-$ Reimbursement of $h_{y}$

Figure 4: Again, welfare is presented as share of predicted baseline with population transition. Pareto improvements are generated when Social Security and Medicare taxes are unexpectedly eliminated. Reimbursing young agents' time supplying care on the informal market $h_{y t}$ at the market rate $w_{t}$ also yields Pareto improvements.

scheme. Lifetime welfare of all agents over the 21st century is improved from baseline under the reimbursement scheme, though again the most notable improvement is for diseased agents. This finding is particularly promising since growth is relatively unaffected by such a scheme, yet all agents are better off. Further, reimbursement schemes are already implemented in certain states. Our results suggest that more adoption of these policies will lead to welfare improvements across the board. 


\subsection{Steady State Comparative Statics}

Using the calibrated parameters from Table 3 we simulate steady state outcomes under different working-age population ratios and compare them to an economy without a social insurance system. We present selected policies and aggregate outcomes in Figure 5. The model predicts that both labor supply and total time spent providing informal care is higher when the social safety net is eliminated. Young people sacrifice leisure time for work because wages are higher and pick up the slack caring for their elders at all levels of wapr. All values are monotonic in wapr, though the signs of some of the relationships may be surprising. Not surprisingly, labor and output are increasing in wapr, but work hours are increasing because wages are decreasing: holding productivity fixed, wages are bid down as the number of workers increases. Steady state savings rates increase in wapr as a response to higher interest rates, driven up by increases in the labor supply forcing firms to acquire more capital to efficiently utilize the skills of increasing numbers of workers. U.S. personal savings rates have generally fallen since the 1950's, from $11.3 \%$ in January 1959 when wapr was at 5.176 to $6.3 \%$ in December 2016 with a wapr of 3.475, confirming the validity of the sign of the relationship we observe here.

For each of the $\tau=0$ and $\tau=0.153$ case, we simulate expected lifetime utility for a young agent who has not yet realized his old-age disease status as well as realized lifetime utility for both diseased $d=1$ and non-diseased $d=0$ old agents. ${ }^{25}$ Figure 6 presents these welfare values as functions of wapr. This exercise demonstrates that for small enough wapr, higher social insurance taxes can lead to higher steady state lifetime welfare for diseased agents, though not non-diseased agents. In steady state, reducing

\footnotetext{
${ }^{25}$ Let $\mathbb{E} u(d)$ be expected lifetime steady state utility, $u(d=1)$ be realized lifetime utility for a diseased agent, and $u(d=0)$ be realized lifetime utility for a non-diseased agent. These values are as follows:

$$
\begin{aligned}
& \mathbb{E} u(d)=u_{y}+\beta \cdot\left[\psi \cdot u_{o}(1)+(1-\psi) \cdot u_{o}(0)\right] \\
& u(d=1)=u_{y}+u_{o}(1) \\
& u(d=0)=u_{y}+u_{o}(0)
\end{aligned}
$$


taxes from the 2016 value of $\tau=0.153$ is Pareto improving as long as wapr $>2.434$. Why is this? Consider informal care time supplied by young $h_{y t}$. Figure 5 shows that time supplied per-individual is decreasing in wapr though aggregate time supplied is increasing in wapr. At a certain threshold, the extensive margin - the total number of young people - dominates the intensive margin - the time supplied by each young person, leading to adverse welfare effects on diseased old.
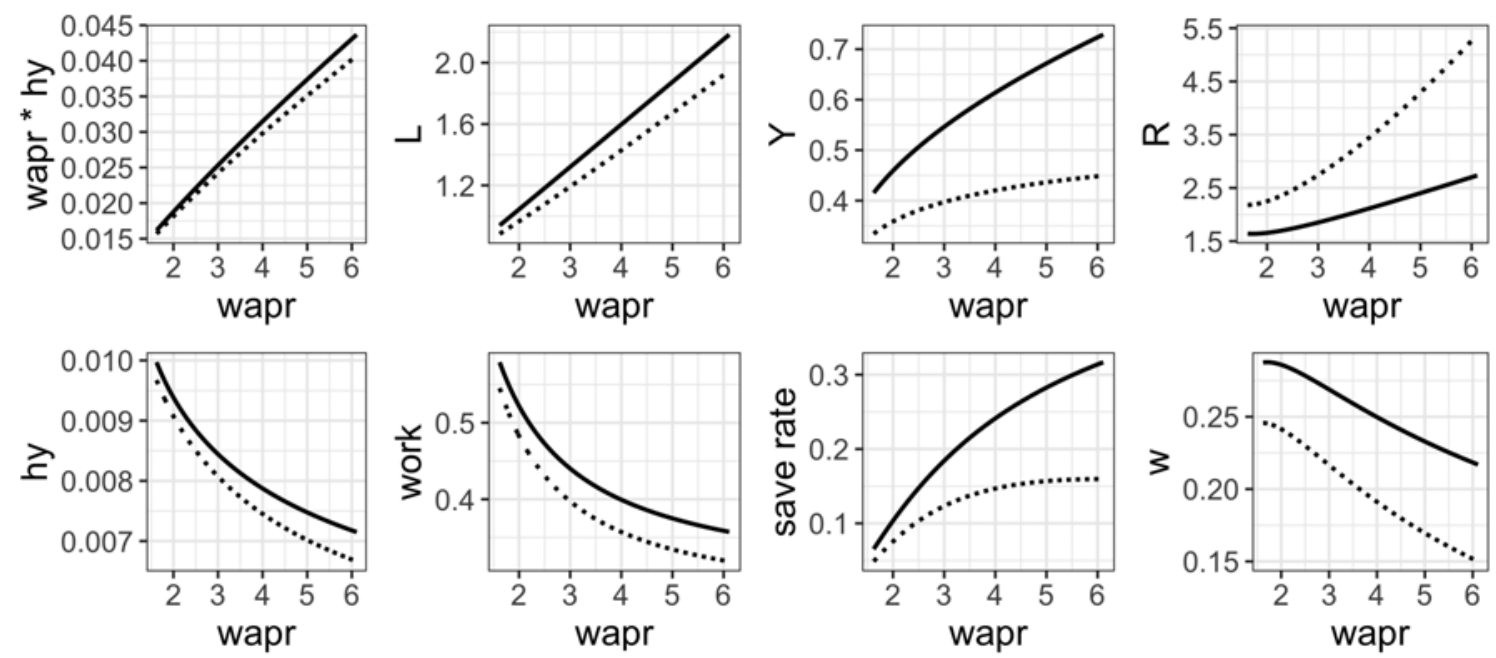

$$
\cdots \tau=0.153-\tau=0
$$

Figure 5: Here we plot steady state outcomes as a function of wapr and different tax rates. Solid lines represent economic variables when the government chooses $\tau=0$, and dotted lines represent variables under $\tau=0.153$, the 2016 Social Security and Medicare tax rate.

Notice also that diseased old utility falls faster than non-diseased utility as wapr decreases. This is because the decline in the extensive margin drives down total off-market time supplied by young agents as wapr falls, even though every individual young agent is supplying more informal care time on the intensive margin. Meanwhile, as wapr increases, diseased lifetime utility increases faster than non-diseased lifetime utility as the total supply of informal care time increases, allowing diseased agents to supplement their market consumption with increasing amounts of care from their children. Since these are steady state comparisons only, they should be interpreted with caution as such analyses fail to account for productivity gains. We present them to illustrate the co-dependence of 
lifetime welfare on both wapr and $\tau$.

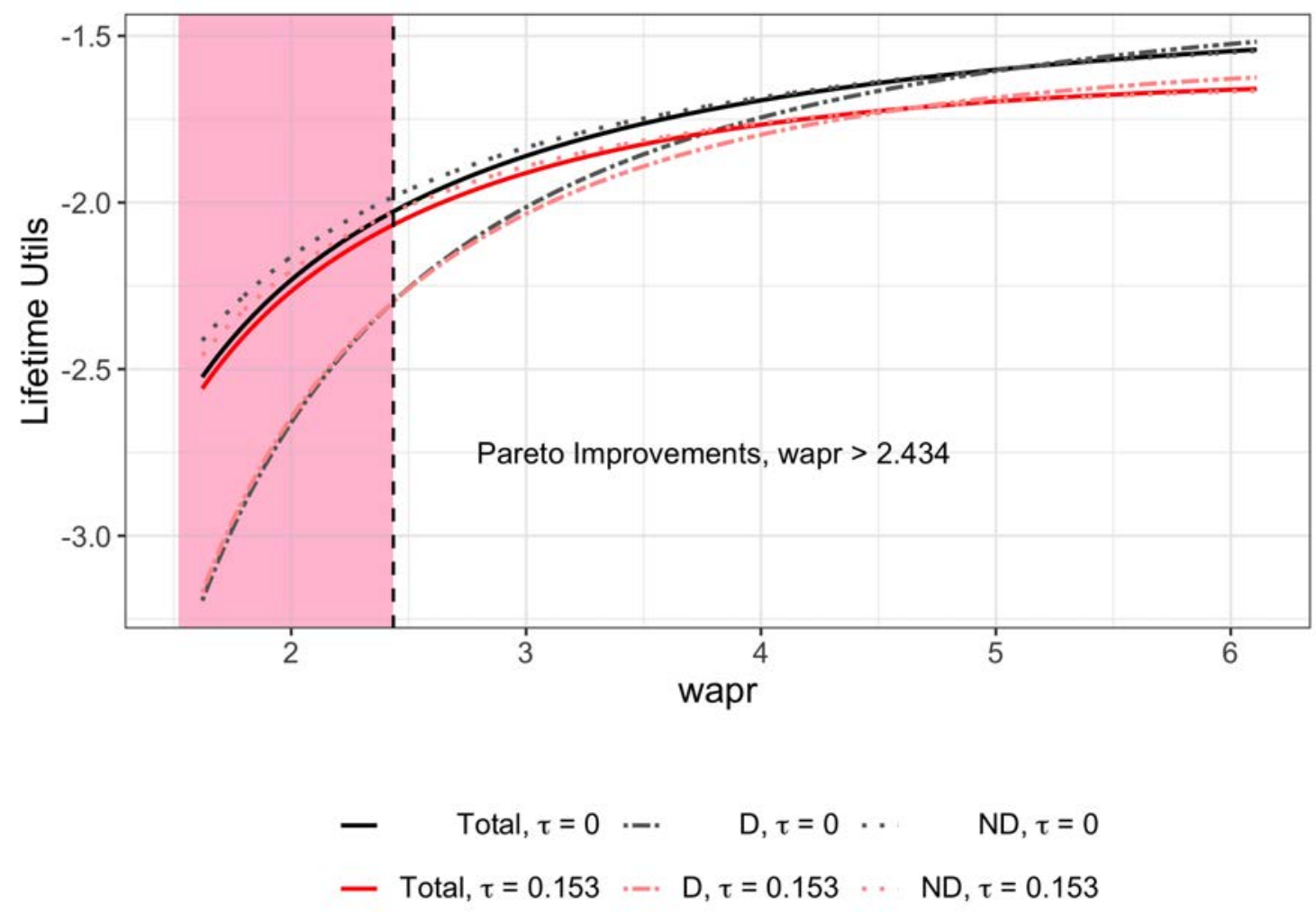

Figure 6: For all wapr $\leq 2.434$ - in the pink box to the left of the dashed vertical line - diseased agents are worse off with $\tau=0$ than under the baseline 2016 tax rate.

\section{Conclusion}

Including both idiosyncratic health risk and a motive for young people to engage in informal care of their elders allows the standard, two-period overlapping generations model with production and social insurance taxes to broadly describe the observed decline in aggregate output growth since the 1950s. The model we present qualitatively describes and matches the observed tradeoffs from the ATUS data that agents face when making a decision to provide time on the informal market. These results are important because they should encourage researchers to take seriously the model's predictions about future economic outcomes in an environment with a rapidly aging population. Due to incom- 
plete markets, the rate at which the population ages can adversely impact lifetime welfare of diseased agents when not enough young agents are alive to supply informal care. In counterfactual simulations, reimbursement of informal care time and cures for dementialike diseases improve both growth and welfare over the U.N.'s medium-variant projected population distribution throughout the $21^{\text {st }}$ century. These results should encourage policy makers to consider how the age-distribution and idiosyncratic risk affect economic aggregates when proposing reforms to address stagnating growth. Aging appears to have broad impacts on long-run GDP growth, regardless of old-age disease risk. Further, finding cures for diseases like Alzheimer's and dementia can lead to modest growth improvements, but more importantly such cures are Pareto improving. 


\section{References}

Alzheimer's Association. 2011. “Alzheimer's Association Report: 2011 Alzheimer's disease facts and figures". Alzheimer's \& Dementia 7:208-244.

Azomahou, Théophile, Bity Diene, and Luc Soete. 2009. "The role of consumption and the financing of health investment under epidemic shocks". United Nations University Working Paper Series: \#2009-006.

Becker, Gary. 1965. "A Theory of the Allocation of Time". The Economic Journal 75 (299).

Bureau of Labor Statistics. 2017. “American Time Use Survey (ATUS)”. Visited on 11/20/2017. https://www.bls.gov/tus/home.htm.

Carmichael, F., S. Charles, and C. Hulme. "Who will care? Employment participation and willingness to supply informal care".

Carroll, Christopher. 2006. "The method of endogenous gridpoints for solving dynamic stochastic optimization problems". Economics Letters 91.

Cooley, Thomas, and Espen Henriksen. 2018. "The Demographic Deficit". Journal of Monetary Economics 93.

DeJong, David, and Chetan Dave. 2011. Structural Macroeconometrics. Second. Princeton University Press.

DeNardi, Mariacristina, Eric French, and John Jones. 2010. “Why Do the Elderly Save? The Role of Medical Expenses". Journal of Political Economy 118 (1).

Edwards, Ryan. 2008. "Health Risk and Portfolio Choice". Journal of Business \& Economic Statistics $26(4)$.

French, Eric, and John Bailey Jones. 2011. "The Effects of Health Insurance and SelfInsurance on Retirement Behavior". Econometrica 79 (3). 
Hall, Robert, and Charles Jones. 2007. "The Value of Life and the Rise in Health Spending". The Quarterly Journal of Economics.

Hodrick, Robert, and Edward Prescott. 1997. "Postwar U.S. Business Cycles: An Empirical Investigation". Journal of Money, Credit, and Banking 29 (1).

Hubbard, R Glenn, Jonathan Skinner, and Stephen Zeldes. 1995. "Precautionary Saving and Social Insurance". Journal of Political Economy 103 (2): 360-399.

Hurd, Michael, et al. 2013. "Monetary Costs of Dementia in the United States". The New England Journal of Medicine 368 (14).

Knickman, James, and Emily Snell. 2002. “The 2030 Problem: Caring for Aging Baby Boomers". HSR: Health Services Research 37 (4).

Krueger, Dirk, and Alexander Ludwig. 2007. “On the consequences of demographic change for rates of returns to capital, and the distribution of wealth and welfare". Journal of Monetary Economics 54:49-87.

Leigh, Andrew. 2010. "Informal care and labor market participation". Labour Economics 17.

Lepore, Michael, Abby Ferrell, and Joshua Wiener. 2017. “Living Arrangements of People with Alzheimer's Disease and Related Dementias: Implications for Services and Supports". Research Summit on Dementia Care (white paper).

Mommaerts, Corina. 2017. "Are Coresidence and Nursing Homes Substitutes? Evidence from Medicaid Spend-Down Provisions". Working Paper.

— . 2016. "Long-Term Care Insurance and the Family". Working Paper.

Muurinen, Jaana-Marja. 1986. “The Economics of Informal Care: Labor Market Effects in the National Hospice Study". Medical Care 24 (11).

National Institute on Aging. 2011. Global Health and Aging. 
National Research Council. 2001. Preparing for an Aging World: The Case for Cross-National Research.

Palumbo, Michael. 1999. "Uncertain Medical Expenses and Precautionary Saving Near the End of the Life Cycle". The Review of Economic Studies 66 (2).

Prescott, Edward. 2004. "Why Do Americans Work So Much More Than Europeans?" Federal Reserve Bank of Minneapolis Quarterly Review 28 (1).

United Nations: Department of Economic and Social Affairs. 2017. "World Population Prospects: The 2017 Revision". Visited on 07/31/2017. https : //esa . un . org/unpd/ wpp/Download/Standard/Population/.

Van Houtven, Courtney Harold, Norma Coe, and Meghan Skira. 2013. "The effect of informal care on work and wages". Journal of Health Economics 32. 


\section{A Proofs}

Lemma 1. For all $v>0$, Assumption 1 holds.

Proof. This proof is trivial, but requires the assumption that $c>v$ so that Inada conditions are satisfied and $c$ is thus feasible. Under that assumption, clearly $\ln (c-v)<\ln c$.

Lemma 2. If $0<v<c_{o t}(1)-c_{o t}(0)$ then the ratio of the marginal utility of non-diseased consumption to diseased consumption is such that $M U_{o t}(0) / M U_{o t}(1)>1$.

Proof. Assume Inada conditions are satisfied such that $c_{o t}(1)>v$ and $c_{o t}(0)>0$. Given Lemma $1, v>0$. Note that:

$$
\begin{aligned}
& M U_{o t}(1)=\frac{1}{c_{o t}(1)-v} \\
& M U_{o t}(0)=\frac{1}{c_{o t}(0)}
\end{aligned}
$$

Rearranging the inequality in the premise we get

$$
\begin{aligned}
& c_{o t}(0)-v<c_{o t}(0)<c_{o t}(1)-v \\
\Rightarrow & \frac{1}{c_{o t}(0)}>\frac{1}{c_{o t}(1)-v}
\end{aligned}
$$

Corollary 1. Aggregate growth $g_{Y, t}$ depends only on wapr ${ }_{t}$, not population levels.

Proof. Define the period $t$ gross output growth rate as $\left(1+g_{Y, t}\right)=\frac{Y_{t}}{Y_{t-1}}$. Note that

$$
Y_{t}=N_{y t} \cdot\left(1+g_{z}\right)^{t} \cdot a_{y t}^{\alpha}\left(1-l_{y t}-h_{y t}\right)^{1-\alpha}
$$


So

$$
\left(1+g_{Y, t}\right)=\frac{Y_{t}}{Y_{t-1}}=\left(1+g_{N}\right)\left(1+g_{z}\right)\left(\frac{a_{y t}}{a_{y, t-1}}\right)^{\alpha}\left(\frac{1-l_{y t}-h_{y t}}{1-l_{y, t-1}-h_{y, t-1}}\right)^{1-\alpha}
$$

In Proposition 1 we showed that household policies depend only on wapr $r_{t}$ Thus $g_{Y, t}$ depends only on wapr.

Proposition 2. Assume the survival rate $s_{0, t+1}=s_{0}$ is constant and the diseased old distribution $\psi_{t}=\psi$ is stationary. Then along a BGP the working-age population ratio wapr is constant and given by

$$
w a p r=\frac{1+g_{N}}{s_{0}}
$$

Proof. The population of young agents entering the economy in period $t$ is

$$
N_{y t}=\left(1+g_{N}\right) N_{y, t-1}
$$

The population of old agents evolves according to

$$
N_{o t}=s_{o} N_{y, t-1}
$$

Substituting for $N_{y, t-1}$ we can write:

$$
\frac{N_{y t}}{N_{o t}}=\frac{1+g_{N}}{s_{o}}
$$

Note that $\frac{N_{y t}}{N_{o t}}$ is the working-age population ratio wapr. The right-hand side of the above does not depend on $t$. Thus:

$$
w a p r=\frac{1+g_{N}}{s_{o}}
$$




\section{B Calibration}

\section{B.0.1 Setting $\rho$ - Ratio of Diseased to Non-Diseased Benefits}

We calibrate $\rho$ by using estimates from Hurd et al. (2013) and Mommaerts (2016). Mommaerts (2016) uses RAND Health and Retirement Study (HRS) data to estimate median permanent income (\$14,157 in 2010 dollars) of sample respondents over age 65 from 1998-2010. We then use the Social Security Administration's rule of thumb permanent income replacement rate (0.4) to compute the implied Social Security benefits for the median retiree:

$$
14,157 \cdot 0.4=5,662.80
$$

Using HRS data, Hurd et al. (2013) estimates that average total annual Medicare spending for demented individuals is $\$ 5,226$. To compute a baseline for total benefits received by diseased agents we add $\$ 5,226$ to Equation (B.1) to get $\$ 10,888.80$. The steady state ratio of diseased to non-diseased benefits is:

$$
\rho=\frac{10,888.80}{5,662.80}=1.923
$$

\section{B.0.2 Steady State Equations}

The de-trended steady state conditions are below. In order they are as follows (B.3) thru (B.6) comprise the young agent's intertemporal consumption condition, intratemporal consumption/leisure condition, intratemporal leisure/hospice care condition, and bud-

\footnotetext{
${ }^{26}$ Note that we substitute $s_{0}=\frac{1+g_{N}}{\text { wapr }}$ and take $z_{0}=\left(1+g_{N}\right)^{\alpha}$.

${ }^{27}$ The equations presented here are first-order conditions after composing flow utility with the home production functions.
} 
get constraint. (B.7) thru (B.8) define the old agents' market goods conditions. (B.9) and (B.10) describe the equilibrium factor prices. (B.11) describes the accidental bequest condition and (B.12) is the government budget constraint. ${ }^{26} 27$

$$
\begin{aligned}
& \frac{\gamma}{x_{y}^{*}}=\beta \cdot \frac{1+g_{N}}{w a p r} \cdot R^{*}\left[\psi \frac{1-\sigma}{x_{o}^{*}(1)^{1-\sigma}\left(h_{o}^{*}\right)^{\sigma}-v}\left(\frac{h_{o}^{*}}{x_{o}^{*}(1)}\right)^{\sigma}+(1-\psi) \frac{1}{x_{o}^{*}(0)}\right] \\
& \frac{\mu}{l_{y}^{*}}=\frac{\gamma}{x_{y}^{*}} w^{*}(1-\tau) \\
& \frac{\mu}{l_{y}^{*}}=\eta \cdot \frac{\sigma}{x_{o}^{*}(1)^{1-\sigma}\left(h_{o}^{*}\right)^{\sigma}-v}\left(\frac{h_{o}^{*}}{x_{o}^{*}(1)}\right)^{\sigma-1} \frac{w a p r}{\psi} \\
& x_{y}^{*}+a_{y}^{*} \leq R^{*} \cdot b_{y}^{*}+w^{*} \cdot(1-\tau) \cdot\left(1-l_{y}^{*}-h_{y}^{*}\right) \\
& x_{o}^{*}(1) \leq R^{*} \cdot a_{y}^{*}+\rho \cdot T^{*}(0) \\
& x_{o}^{*}(0) \leq R^{*} \cdot a_{y}^{*}+T^{*}(0) \\
& R^{*}=1+\left(1+g_{N}\right) \alpha\left(\frac{\left(1-l_{y}^{*}-h_{y}^{*}\right)}{a_{y}^{*}}\right)^{1-\alpha}+\delta \\
& w^{*}=(1-\alpha)\left(\frac{a_{y}^{*}}{1-l_{y}^{*}-h_{y}^{*}}\right)^{\alpha} \\
& b_{y}^{*}=a_{y}^{*} \frac{1-\frac{1+g_{N}}{w a p r}}{1+g_{N}} \\
& T^{*}(0)=\frac{w^{*} \cdot \tau \cdot w a p r \cdot\left(1-l_{y}^{*}-h_{y}^{*}\right)}{\rho \cdot \psi+1-\psi}
\end{aligned}
$$

The steady state does not admit a neat closed form analytical solution due to the nonlinearities in (B.5). We solve the steady state using Powell's hybrid method. 